ISBN 978-93-84422-79-0

6th International Conference on Humanities, Interdisciplinary Studies, Hospitality and Tourism

Management (HISHTM-17)

Singapore Aug. 10-11, 2017

\title{
Study of Consumers Preferences on Bell Pepper Jelly
}

\author{
Shang-Hui Li ${ }^{1}$, Jia-Wun Xie, Yi-Ru Zhao, Ting-Jyun Lin, Zi-Hao Liu, and Bo-Xun Zhang \\ Department of Food and Beverage Management, Far East University \\ No.49, Zhonghua Rd., Xinshi Dist., Tainan City 74448, Taiwan (R.O.C.) \\ ${ }^{1}$ E-mail:a0956358700@gmail.com
}

\begin{abstract}
Bell peppers are rich in vitamin C, lycopene and other nutrients. However, Peppers have some special taste which often deterred some consumers to purchase it. The study produced the bell pepper into jelly to investigate whether consumers have changed their appetite to pepper, thus increasing their purchase intention. 130 consumers were selected at Tainan area to participate in the sensory evaluation of preferences by convenience sampling, 5-point Likert scale was used and reusable rating was permitted. The evaluation content included the appearance, flavor, crispness, smooth degree, overall acceptability and purchase intention. The finding results showed that the mixed jelly, made by yellow pepper juice, apple juice and jelly powder, is welcomed by consumers. Further, the mixed jelly is better than other jellies on each evaluation item and there are significant differences.
\end{abstract}

Keywords: Bell Pepper, Jelly, Sensory Evaluation, Purchase Intention

\section{Introduction}

Sweet pepper is a nutritious food, but some consumers, especially the children, their acceptance are not so high to the unique flavor of the pepper. In this study, some other fresh fruit and vegetable were added to the sweet pepper. The study tried to save the nutrition of sweet pepper, also try to change the special flavor of sweet pepper hoping to allow the consumers to change their ideas to sweet peppers.

Jelly is a kind of snack for men, women and children. Its tastes smoothly, and is a natural rubber production. In this study, sweet pepper was applied in jelly. The color of sweet pepper can attract many consumers to buy it. Consumers also intake nutrition from sweet pepper in addition to the edible jelly. But, till now, few research data have been found to explore the effect of sweet pepper applied in jelly. In this study, the sweet pepper was selected as a research item to process the sensory evaluation of consumer taste to explore the purchase intension to sweet pepper jelly and preferences..

\section{Literature Review}

\subsection{Sweet Pepper}

Contributions Sweet pepper is a native to the South America in which not spicy is called sweet pepper. And the spicy one called hot pepper, collectively referred to as pepper, and scientific name is capsicum annuum $\mathrm{L}$.

(1). Sweet pepper is rich in dietary fiber, $\beta$-carotene, vitamin B6, vitamin C, potassium, calcium and nicotine etc.. Beta-carotene from sweet pepper can be converted into vitamin A in the liver, which can protect the eyes, against cataracts (3). Also, it is with high vitamin C, 2 times more than citrus (1).

\subsection{Sensory Evaluation}

Manuscript requirements Institute of Food Technologists, IFT, considered that sensory evaluation is in a scientific way to measure and analyze the subject of food through the feeling of vision, smell, taste, touch and 
hear. Sensory evaluation is the objective detection tool of food with a scientific method, (4). The food evaluation includes the appearance, flavor, crispness, taste, quality, safety, and nutrition. So the sensory evaluation technique is indispensable 〔5〕. In this study, the sensory characteristics of the sample score could be created in accordance with the respondents' own feelings.

\subsection{Purchase Intention}

It can be regarded as a decision-making process while consumers decide to buy a product. That is, consumers assessed and finally decide whether to buy after the collection of product-related information. The purchase intention was usually the primary key in the process of consuming decision-making. Intention is the subjective probability of being engaged in a particular act and extends through the same concept, according to the definition of Fishbein and Ajzen [6]. Reynolds and Wells [7] described consumer characteristics as descriptive and predictive behaviors. They pointed out that the purchase intention to predict the buying behavior was more accurate than predict the preference behavior. Fandos and Flavian 〔 $[8]$ argued that the willingness to buy can reflect the foreseeable behavior of the consumers, meaning that the purchase intention will predict the next product or brand to buy.It was more accurate to forecast sales trends based on buying intentions [9] . Consumers' willingness to buy usually depends on interests and values 〔 10$]\lceil 11]$.

\section{Research Method}

This study was divided into preliminary trials and formal tests. The preliminary trials were selected 15 experienced students from Far East University, Tainan. Next, to select the four popular of sweet pepper jelly as the formal test samples after three trials were analyzed. Formal test recipe was as shown in Table 1.

TABLE I: Recipe of Sweet Pepper Jelly

\begin{tabular}{ccccc}
\hline$\#$ & 997 & 178 & 288 & 679 \\
\hline $\begin{array}{c}\text { Yellow pepper } \\
\text { Red pepper }\end{array}$ & $150 \mathrm{~g}$ & $150 \mathrm{~g}$ & $150 \mathrm{~g}$ & $150 \mathrm{~g}$ \\
White sugar & $45 \mathrm{~g}$ & $30 \mathrm{~g}$ & $30 \mathrm{~g}$ & $30 \mathrm{~g}$ \\
Jelly powder & $12 \mathrm{~g}$ & $12 \mathrm{~g}$ & $12 \mathrm{~g}$ & $6 \mathrm{~g}$ \\
Agar powder & & & $75 \mathrm{~g}$ \\
Water & $300 \mathrm{~g}$ & $150 \mathrm{~g}$ & $150 \mathrm{~g}$ & $225 \mathrm{~g}$ \\
Apple juice & & $150 \mathrm{~g}$ & $150 \mathrm{~g}$ & \\
\hline
\end{tabular}

Formal questionnaires to facilitate the sampling method, for Taiwan consumers, included gender, age, occupation, education background, appearance, flavor, sweetness, crispness, smooth degree, overall acceptability and purchase intention. The score is divided into five points from 1, very dislikes, to 3, ordinary, and finally, 5, very much like (repeatable to points). Issued a total of 130 questionnaires, and 120 valid questionnaires were collected. The results of the questionnaires were analyzed by SPSS12.0 statistical software.

\section{Data Analysis and Results}

\subsection{Basic Data Analysis}

Data sample structured of 56 males and 64 females. 73 respondents are under the age of 20, a total of 100 college students $(83.5 \%)$. 


\subsection{Differences in Analysis}

\subsubsection{Differences Analysis in Overall Acceptance}

There was no significant difference on overall acceptance between \#178 (mean 2.90, the jelly added with red pepper and apple juice, and \#679 (mean 2.90, agar powder added with red pepper and apple juice ). While most respondents could accept the \# 288 (mean 3.18, jelly added with yellow pepper and apple juice ). And the overall satisfaction has a significant difference compared with the other three products indicating that most respondents were satisfied with \# 288 (mean 3.18,jelly added with yellow pepper and apple juice) . Differences in overall acceptance were as shown in Table 2.

TABLE II: Differences in Overall Acceptance for Different Jelly

\begin{tabular}{cccccc}
\hline Items & $\#$ & Number & $\begin{array}{l}\text { Average/ Standard } \\
\text { deviation }\end{array}$ & F test & Significance \\
\hline Overall & 288 & 120 & $3.18 \pm 1.076^{\mathrm{b}}$ & & \\
Acceptance & & 120 & $2.90 \pm 1.118^{\mathrm{ab}}$ & \\
& 679 & 120 & $2.90 \pm 1.159^{\mathrm{ab}}$ & & \\
& 997 & 120 & $2.63 \pm 1.107^{\mathrm{a}}$ & & \\
\hline
\end{tabular}

Note 1: $* \mathrm{P}<0.05$ significant, $* * \mathrm{P}<0.01$ very significant, $* * * \mathrm{P}<0.001$ very very significant

Note $2: 178$ (Red pepper + Apple juice + Jelly powder $) ; 288$ (Yellow pepper + Apple juice + Jelly powder) ; 679 (Red pepper + Apple juice + Agar powder) ; 997 (Red + Sugar + Jelly Powder)

\subsubsection{Differences Analysis in Purchase Intention}

On purchase intension, there were a significant difference among the respondents \#178 (mean 2.55, jelly added with red pepper and apple juice ) \#288 (mean 2.67,jelly added with red pepper and apple juice) , and \#997 (mean 2.24, jelly added with red pepper and sugar (Table 3). The mean of the above three were under 3 which were shown the not high purchase intension.

TABLE II: The Difference Analysis of Purchase Intension for Different Jelly

\begin{tabular}{cccccc}
\hline Items & $\#$ & Number & $\begin{array}{l}\text { Average/ Standard } \\
\text { deviation }\end{array}$ & F test & Significance \\
\hline Purchase & 178 & 120 & $2.55 \pm 1.158^{\mathrm{b}}$ & & \\
Intension & 288 & 120 & $2.67 \pm 1.146^{\mathrm{b}}$ & 3.172 & $0.024^{*}$ \\
& 679 & 120 & $2.50 \pm 1.137^{\mathrm{ab}}$ & & \\
\hline
\end{tabular}

Note $1: * \mathrm{P}<0.05$ significant, $* * \mathrm{P}<0.01$ very significant, $* * * \mathrm{P}<0.001$ very very significant

Note 2:178 (Red pepper + Apple juice + Jelly powder ) ; 288 (Yellow pepper + Apple juice + Jelly powder) ; 679 (Red pepper + Apple juice + Agar powder) ; 997 (Red + Sugar + Jelly Powder)

\section{Conclusion and Suggestion}

The finding results showed that the mixed jelly, made by yellow pepper, apple juice and jelly powder, is welcomed by consumers. Further, the mixed jelly is better than other jellies on each evaluation item, including the appearance, flavor, sweetness, crispness, smooth degree, overall acceptability and purchase intention, and there are significant differences. Maybe this recipe can cover the spicy taste of the sweet pepper. The results also showed that sweet pepper combined with jelly will be the potential dessert for sales. 
This study is limited by human resource, financial ability, time range, the willingness of the respondents, and other factors. Hope that future researchers can expand the age of research, for the different age to develop the most appropriate products. Try to add the different flavors of natural ingredients, developed the baking products with sweet pepper, and different cooking methods of sweet pepper recipes. Also, the future researchers can collaborate with TV media, Internet (such as Facebook, LINE etc.) to promote sweet pepper benefits, and with the local farmers to grow up sweet pepper, so that more consumers could understand the sweet pepper.

\section{References}

[1] Y.R.WU, Five color fruits and vegetables health book, Taipei, face sread Publish,2006.

[2] Food and Drug Administration, MOHW, Taiwan,2016/12/3 from http://www.fda.gov.tw/TC/index.aspx, 2016.

[3] M.Y.LIAO, Rainbow Color Vegetitizer Heart Care Cancer- Pepper。Changhua Christian Hospital, vol. 93, 2014.

[4] S.M. Ou, Food sensory evaluation and practice,pp.6-134, Wagner Publishing Co.,Ltd,2012.

[5] YAO, Sensory evaluation introduction, application and future development。Taiwan Food News, vol. 192, pp. 44, 2002.

[6] N.Z. YAO, Sensory evaluation introduction, application and future development。Taiwan Food News, vol. 192, pp. 44, 2002.

[7] F. D. Reynolds, and W. D. Wells, Consumer Behavior, New York: Mc Graw-Hill Book Co., 1997.,

[8] C. Fandos and C. Flavian, "Intrinsic and extrinsic quality attributes, loyalty and buying intention: an analysis for a PDO product, ” British Food Journal, vol.108, no.8, pp. 646-662, 2006

[9] J. S. Armstrong, V. G. Morwitz and V. Kumar, "Sales forecasts for existing consumer products and services: Do purchase intentions contribute to curacy," International Journal of Forecasting, vol. 16, no.3, pp. 383-397, 2000.

[10] V. A. Zeithaml, "Consumer Perceptions of Price, Quality, and Value: A Means-End 21Model and Synthesis of Evidence," Journal of Marketing vol. 52, no.3, pp. 2-22, 1988.

[11] W. B. Dodds, K. Monroe, and D. Grewal, "Effects of price, brand, and store informationon buyers' product evaluations," Journal of Marketing Research. vol. 28, pp. 307-319, 1991. 